monitored after endogenous stimulation did not affect the release of cholecystokinin. ${ }^{910}$ Similarly, bombesin ${ }^{11}$ and glucagon ${ }^{12-14}$ have been shown to decrease food intake, but no information is available on the effect of cimetidine or acid reduction on the release of these peptides.

Results of the current trial raise several questions that need to be clarified in future investigations. The mechanism of action should be elucidated with regard to the possible involvement of gastrointestinal hormones that might serve as afferent signals to the hypothalamus. Whether other means of reducing gastric acid secretion have the same effect should be tested. Until this is known cimetidine suspension may serve as a valuable adjunct to diet in treating obesity, though additional research both on the long term effect of cimetidine suspension and on its mechanism of action in overweight subjects is necessary before general recommendations can be given.

This study was supported by a grant from SmithKline Beecham, who also provided the drugs. Special thanks to Drs Ludvig Trang and Harriet Ohlsson, of SmithKline Beecham, Sweden, and to Dr Erling Thom medical director, Medstat Research, Norway, for their help and support.
1 Simopoulos AP. Characteristics of obesity: an overview in human obesity. Ann NY Acad Sci 1987;499:4-13.

Simopoulos AP, Van Itallie TB. Body weight, health and longevity. Ann Intern Med 1984;100:285-95.

3 Hubert HB, Feinleib M, McNamara PM, Castelli WP. Obesity as an independent risk factor for cardiovascular disease: a 26-year follow-up of independent risk factor for cardiovascular disease: a 26-year follow-up o

participan in the FA, Sam

anson JE, Colditz GA, Stampfer MJ, Willet WC, Rosner B, Monson RR, et al. A prospective study of obesity and the risk of coronary heart disease in women. N Engl f Med 1990;322:882-9.

5 Wing RR, Jeffery RW. Outpatient treatments of obesity: a comparison of methodology and clinical results. Int f Obesity 1979;3:261-79.

6 Walan A, Strom M. Metabolic consequences of reduced gastric acidity. Scand f Gastroent 1985;20(supp 111):24-9.

7 Pi-Sunyer X, Kissileff HR, Thornton J, Smith GP. C-terminal octapeptide of cholecystokinin decreases food intake in obese men. Physiol Behav 1982;29: 627-30.

8 Stacher G, Steinringer H, Schmierer G, Schneider C, Winklehner S. Cholecystokinin octopeptide decreases intake of solid food in man. Peptides 1982:3:133-6.

9 Anagnostides A, Chadwick VS, Selden AC, Maton PN. Sham feeding and pancreatic secretion. Gastroenterology 1984;87:109-14.

10 Bozhurt T, Adler G, Leferink S, Amold R. Volume and enzyme kinetics of human pancreatic secretion after endogenous stimulation with the Lundh test meal. Int $\mathcal{J}$ Pancrat 1990;6:281-93.

11 Muurahainen NE, Kissileff HR, Thornton J, Pi-Sunyer FX. Bombesin: another peptide that inhibits feeding in man [abstract]. Soc Neurosci 1983;9:183.

12 Penick SB, Hinkle Jr LE. Depression of food intake in healthy subjects by glucagon. $N$ Engl I Med 1961;264:893-7.

13 Penick SB, Hinkle Jr LE. The effect of glucagon, phenmetrazine and epinephrine on hunger, food intake and plasma nonesterified fatty acids. Am f Clin Nutr 1963;13:1 10-4.

14 Schulman JL, Carleton JL, Whitney G, Whitehorn JC. Effect of glucagon on food intake and body weight in man. $\mathcal{F}$ Appl Physiol 1957;11:419-21.

(Accepted 16 fune 1992)

\section{Department of \\ Endocrinology, \\ Hvidovre University \\ Hospital,DK-2650 \\ Hvidovre, Denmark \\ Michael Højby Rasmussen, research fellow \\ Leif Breum, research \\ associate \\ Jannik Hilsted, head of \\ department of endocrinology \\ Department of \\ Gastroenterology, \\ Hvidovre University \\ Hospital \\ Teis Andersen, senior \\ registrar \\ Department of \\ Rheumatology, \\ Hvidovre University \\ Hospital \\ Peter C Gøtzsche, senior \\ registrar}

Correspondence to:

Dr Rasmussen.

$B M 7$ 1993;306:1093-6

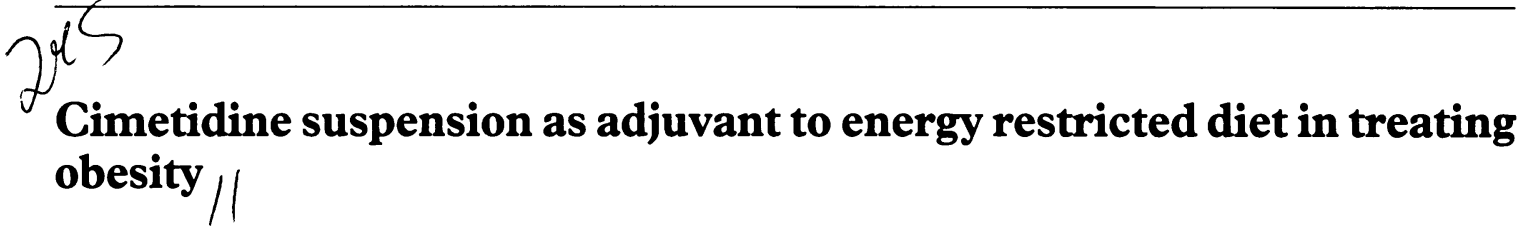

Michael Højby|Rasmussen, Teis Andersen, Leif Breum, Peter CGøtzsche, Jannik Hilsted

Abstract

Objective-To study the effect of cimetidine suspension compared with placebo suspension on weight loss in moderately obese patients taking a $5 \mathrm{MJ} /$ day diet supplemented with dietary fibre. To determine the relation between the effectiveness of the blinding and weight loss.

Design-Randomised double blind study with an eight week parallel group phase and a subsequent eight week crossover or continuation phase.

Setting-Outpatient clinic.

Subjects -60 patients (51 women) aged 18-60.

Main outcome measure-Weight loss.

Results-After eight weeks of treatment the mean weight loss in the cimetidine group $(5.7 \mathrm{~kg})$ was similar to that of the placebo group $(5.9 \mathrm{~kg} ; \mathrm{p}=0.78$, $95 \%$ confidence interval -2.0 to $1.5 \mathrm{~kg}$ ). Body mass index, waist and hip measurements, waist-hip ratio, and systolic and diastolic blood pressures decreased similarly in the two groups. No association was found between weight loss and the patients' ability to guess if they were being given drug or placebo. Correct guesses of current drug were more prevalent than expected by chance $(25 / 37$ correct, $p=0.05$ for the parallel group phase; $26 / 30, p=0.0001$ for the crossover phase).

Conclusions-Cimetidine had no effect on weight loss in moderately obese patients. The study underlines the potential problem that blinding of patients to treatment can be compromised.

\section{Introduction}

In a recent eight week double blind Norwegian trial 60 overweight patients were given $200 \mathrm{mg}$ of cimetidine suspension or placebo 30 minutes before breakfast, lunch, and dinner as adjuvant to a $5 \mathrm{MJ} /$ day (1200 $\mathrm{kcal} /$ day) diet supplemented with $9 \mathrm{~g}$ of dietary fibre.' The mean weight loss during cimetidine treatment was $7.4 \mathrm{~kg}$ greater during treatment with cimetidine than during placebo $(p<0.001)$ and the perception of hunger, measured on a visual analogue scale, was significantly less at all three meals in the cimetidine group. Furthermore, the reductions of abdominal and hip circumferences, as well as the fall in systolic and diastolic blood pressure, were significantly greater in the patients treated with cimetidine.

The suggested mechanisms of action were a suppression of gastric acid or suppression of hunger by blocking histamine $\mathrm{H}_{2}$ receptors. The impact on appetite might help patients to a better and more prolonged compliance with a restricted diet, leading to greater weight loss.

The double blind principle is of great importance in most therapeutic research, especially when the outcome is subjective or may be influenced by subjective beliefs. However, the effectiveness of the blinding in double blind studies can often be questioned. We therefore did a confirmatory eight week double blind parallel group study with cimetidine. To this first phase we added an eight week crossover or continuation phase to expand on the findings of the previous trial. ${ }^{1}$ Furthermore, we examined the success of the blinding and its relation to weight loss.

\section{Patients and methods}

Criteria for entry were age between 18 and 60 years, body mass index between 27 and $39 \mathrm{~kg} / \mathrm{m}^{2}$, and cooperation and motivation for participation. Criteria for exclusion were obesity due to any endocrinological disorder; history of treatment for depression; evidence of severe somatic or psychiatric disease or alcohol misuse; suspicion of active peptic ulcer; pregnancy, 
lactation, or desire to become pregnant; current or recent energy restricted diet; or administration during the previous three months of any drug which might interfere with cimetidine or disturb the metabolism. The study group comprised 51 women and nine men from the outpatient clinic (table I), who gave informed consent for a 16 week study of weight loss.

TABLE I-Data on patients before entering the trial by study group. Values are mean $(S D)$ unless stated otherwise

\begin{tabular}{lcc}
\hline & $\begin{array}{c}\text { Cimetidine } \\
(\mathrm{n}=30)\end{array}$ & $\begin{array}{c}\text { Placebo } \\
(\mathrm{n}=30)\end{array}$ \\
\hline Sex (F/M) & $26 / 4$ & $25 / 5$ \\
Age (years) & $37(11)$ & $37(11)$ \\
Body weight $(\mathrm{kg})$ & $95 \cdot 5(17 \cdot 8)$ & $95 \cdot 9(12 \cdot 8)$ \\
Height $(\mathrm{m})$ & $1 \cdot 69(0 \cdot 09)$ & $1 \cdot 68(0 \cdot 09)$ \\
Body mass index $\left(\mathrm{kg} / \mathrm{m}^{2}\right)$ & $33 \cdot 4(3 \cdot 8)$ & $34 \cdot 1(4 \cdot 1)$ \\
Waist $(\mathrm{cm})$ & $104 \cdot 3(12 \cdot 7)$ & $104 \cdot 0(11 \cdot 7)$ \\
Hip $(\mathrm{cm})$ & $116 \cdot 3(9 \cdot 2)$ & $118 \cdot 4(9 \cdot 8)$ \\
Waist:hip ratio & $0 \cdot 90(0 \cdot 09)$ & $0 \cdot 88(0 \cdot 07)$ \\
Systolic blood pressure (mm Hg) & $127(22)$ & $123(16)$ \\
Diastolic blood pressure (mm Hg) & $81(12)$ & $79(11)$ \\
\hline
\end{tabular}

The study consisted of two consecutive eight week periods. After stratification according to whether or not the patients' body mass index exceeded $33.9 \mathrm{~kg} / \mathrm{m}^{2}$ the patients were randomised in blocks of six to receive either cimetidine or placebo during the first period with a computer generated random code. Patients were allocated to the coded treatment as they entered the study. Patients who received placebo during the first period received cimetidine during the second. Patients who received cimetidine during the first period, however, were assigned to get either cimetidine or placebo during the second period by predetermined randomisation (fig 1). This design was chosen to allow an evaluation of cimetidine over a longer period of treatment.

Cimetidine suspension (Tagamet) $200 \mathrm{mg} / 10 \mathrm{ml}$ and placebo suspension were supplied in identically appearing sachets by SmithKline Beecham, United States. Peppermint flavour was added to both suspensions to cover the taste and smell of cimetidine. Patients took $200 \mathrm{mg}$ of cimetidine suspension or an identical placebo suspension three times daily 30 minutes before breakfast, lunch, and dinner.

The patients were instructed to follow a $5 \mathrm{MJ}$ diet and to supplement this diet with $9 \mathrm{~g}$ per day of testa Triticum tricum fibre (Tricum/Cyanamid, Sweden). To help patients keep account of their energy intake, we used an educational system of isoenergetic and freely exchangeable units illustrated on counters. ${ }^{2}$

\section{ASSESSMENT OF PATIENTS}

Patients were seen at the same time of day, twice before randomisation and weekly thereafter. Every week the patients were asked to report any side effects according to a checklist consisting of nine items plus an open ended question.

Patients were given a written and oral education programme. ${ }^{23}$ All unused drugs were collected, recorded, and checked for compliance every week. Patients returning more than $20 \%$ of the prescribed medication during either study period, and patients who did not attend the clinic at least every second week, were considered non-compliant and ineligible for inclusion in the analyses.

At the end of each treatment period (week 7 and week 15) the patients were asked whether they believed they had received cimetidine or placebo or were unable to guess. They were also asked to indicate one or more reasons for their guess. The following options were available: the suspension was efficient, inefficient, tasted like medicine, did not taste like medicine, caused side effects, did not cause side effects, or other.

Weight was measured to the nearest $0 \cdot 1 \mathrm{~kg}$ with electronic scales (Seca 707, Seca, Copenhagen). Perception of hunger was measured weekly on a visual analogue scale.

The waist and hip circumferences were measured with a flexible tape, maintaining close skin contact without compressing underlying tissues. The waist was defined as the circumference located midway between the lower rib margin and the iliac crests. The hip was defined as the widest circumference over the great trochanters. ${ }^{4}$ Circumferences were obtained with the subjects standing.

Blood pressure was measured in the sitting position after at least 10 minutes' rest. A large cuff $(15 \times 43 \mathrm{~cm}$ bladder) was used when the overarm circumference exceeded $35 \mathrm{~cm}$; otherwise a normal cuff $(12 \times 35 \mathrm{~cm}$ bladder) was used.

Blood haemoglobin, serum sodium, potassium, creatinine, alkaline phosphatases, aspartate aminotransferase, blood glucose, and thyroid hormone concentrations were measured before the trial and at weeks 8 and 16. All measurements were made in the hospital's central laboratory by routine methods. The revised Helsinki declaration was observed, and the study was approved by the Copenhagen municipal ethics committee.

\section{STATISTICS}

On the basis of a previous study we assumed that diet alone would give a mean loss over eight weeks of 6 (SD 2) kg. To detect an extra loss of $2 \mathrm{~kg}$ or more with cimetidine (which we took as being a clinically relevant weight reducing effect) with an $\alpha$ risk of 0.05 (two sided) and a power of 0.90 required 60 patients, allowing for a $30 \%$ withdrawal rate.

Student's $t$ test was used to compare mean weight losses, and $95 \%$ confidence intervals are given. Nonparametric analyses gave similar results. Statistical significance was taken as $\mathbf{p}<0.05$.

Multivariate analyses with linear models were used to relate weight loss to drug, trial period, age, sex, and social class. The weight loss was also related to the patients' guesses about treatment, their correctness, and their reasons. The normal approximation to the binomial distribution was used to judge the correctness of the guesses in the two trial periods. ${ }^{5}$ Paired proportions were compared by the sign test.

\section{Results}

The two treatment groups were comparable at baseline (table I). Fifty five of 60 patients $(92 \%)$ completed the first period and 50 patients (83\%) completed both periods. One patient was withdrawn

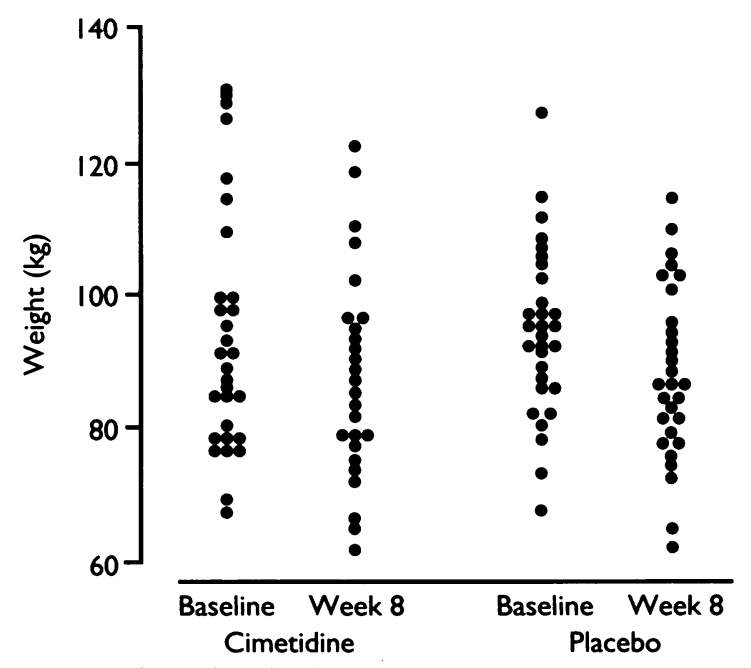

FIG 2-Body weight at baseline and at eight weeks in cimetidine and placebo groups 


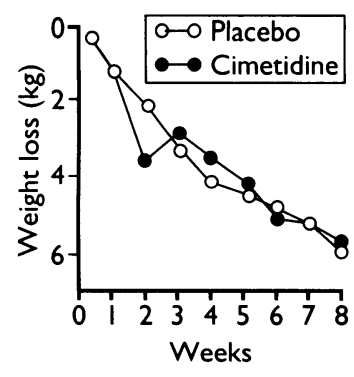

FIG 3-Absolute weight loss during first period in the cimetidine group and in the placebo group. Weight loss was identical in the two groups during the first week because she became pregnant; the remaining patients were withdrawn because of failure to attend or lack of motivation for continuation of the study. All patients complied with the prescribed medication during both periods.

During the first period the mean loss was $5 \cdot 7$ (SD 3.9) $\mathrm{kg}$ in the cimetidine group $(\mathrm{n}=26)$ and 5.9 $(2 \cdot 5) \mathrm{kg}$ in the placebo group ( $\mathrm{n}=29)$ (fig 2$)$. The difference in mean weight loss was insignificant $(p=$ $0 \cdot 78,95 \%$ confidence interval $-2 \cdot 0$ to $1.5 \mathrm{~kg}$ ) (fig 3 ). Mean weight loss in the second period was significantly less than in the first period in all groups $(2.1)(-1.2$ to $2.9) \mathrm{kg}, \mathrm{p}<0.0001)$. No carry over effect was noted (fig 4). The weight loss during both periods was significantly less in women $(7.3 \mathrm{~kg})$ than in men $(12.4 \mathrm{~kg})(p<0.002)$, but no differences were found with age or social class. No effect of cimetidine on perception of hunger was seen (data not shown). The patients' body mass index, waist and hip measurements, waist-hip ratio, and systolic and diastolic blood pressures decreased similarly in the cimetidine group and the placebo group during the first period (table II). Biochemical tests showed no adverse effects from the treatments.

\section{EFFECTIVENESS OF BLINDING}

Only four patients had received cimetidine before the trial, and none of them guessed the drug correctly. Correct guesses of the treatment were significantly more prevalent than expected (table III). There was a non-significant tendency towards more correct guesses during the second period. Of 15 patients who guessed correctly during the first period, only one guessed wrongly in the second, whereas of seven patients who guessed wrongly in the first period, five gave correct guesses in the second $(p=0.22$ for comparison of the two periods). Improvement in the guesses was not confined to patients whose treatment had changed from the first period. Seven of eight patients who received cimetidine during both trial periods guessed the drug correctly after the second period.

Because of the sex difference in weight loss, only women were included in the multivariate analyses. Guesses were not related to weight loss when all

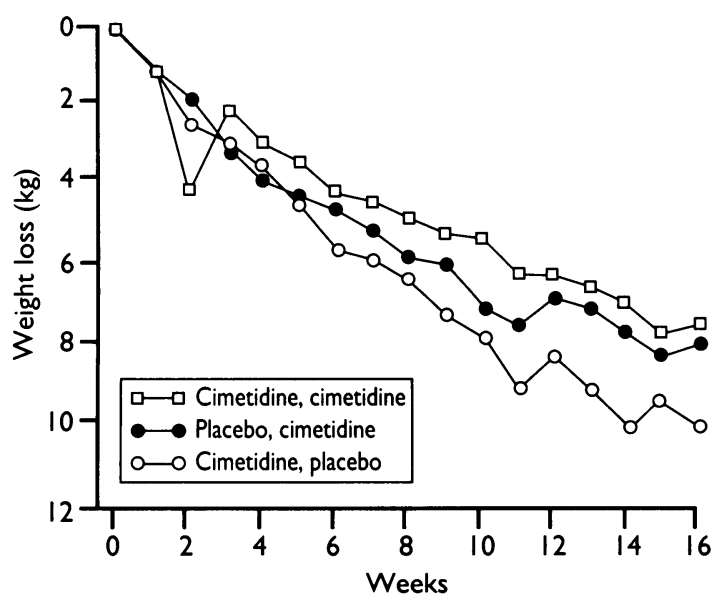

FIG 4-Absolute weight loss during first and second periods. Weight loss was identical for all groups during the first week

TABLE II-Mean (SD) clinical characteristics for cimetidine and placebo group at week 0 and week 8

\begin{tabular}{|c|c|c|c|c|c|}
\hline & \multicolumn{2}{|c|}{ Cimetidine } & \multicolumn{2}{|c|}{ Placebo } & \multirow[b]{2}{*}{ p Value } \\
\hline & $\begin{array}{l}\text { Week 0 } \\
(\mathrm{n}=30)\end{array}$ & $\begin{array}{l}\text { Week } 8 \\
(\mathrm{n}=26)\end{array}$ & $\begin{array}{l}\text { Week 0 } \\
(n=30)\end{array}$ & $\begin{array}{l}\text { Week } 8 \\
(\mathrm{n}=29)\end{array}$ & \\
\hline Body mass index $\left(\mathrm{kg} / \mathrm{m}^{2}\right)$ & $33.4(3.8)$ & $31 \cdot 2(3 \cdot 7)$ & $34 \cdot 1(4 \cdot 1)$ & $31 \cdot 1(5 \cdot 0)$ & 0.78 \\
\hline Waist $(\mathrm{cm})$ & $104 \cdot 3(12 \cdot 7)$ & $98 \cdot 3(10 \cdot 1)$ & $104 \cdot 0(11 \cdot 7)$ & $100 \cdot 1(10 \cdot 6)$ & 0.20 \\
\hline Hip (cm) & $116 \cdot 3(9 \cdot 2)$ & $112.9(8.9)$ & $118 \cdot 4(9 \cdot 8)$ & $115.5(9 \cdot 9)$ & $0 \cdot 18$ \\
\hline Waist:hip ratio & $0.90(0.09)$ & $0.87(0.07)$ & $0.88(0.07)$ & $0.87(0.08)$ & 0.51 \\
\hline Systolic blood pressure $(\mathrm{mm} \mathrm{Hg})$ & $127(22)$ & $120(18)$ & $123(16)$ & $120(15)$ & 0.56 \\
\hline Diastolic blood pressure $(\mathrm{mm} \mathrm{Hg})$ & $81(12)$ & $74(12)$ & 79 (11) & $73(10)$ & 0.94 \\
\hline
\end{tabular}

TABLE III-Patients' guesses about treatment related to actual treatment after seven weeks of the first and second periods of treatment

\begin{tabular}{lcccc}
\hline & \multicolumn{4}{c}{ Guess } \\
\cline { 2 - 4 } & $\begin{array}{c}\text { Cimetidine } \\
\text { group }\end{array}$ & $\begin{array}{c}\text { Placebo } \\
\text { group }\end{array}$ & $\begin{array}{c}\text { Could not } \\
\text { guess }\end{array}$ & p Value \\
\hline Drug in first period: & & & & \\
$\quad$ Cimetidine & 8 & 9 & 9 & 0.05 \\
$\quad \begin{array}{l}\text { Placebo } \\
\text { Drug in second period: }\end{array}$ & 3 & 17 & 9 & 0.0001 \\
$\quad$ Cimetidine & 19 & 4 & 14 & \\
$\quad$ Placebo & 0 & 7 & 6 & 0.0001 \\
\hline
\end{tabular}

Five patients had dropped out at the end of the first period and 10 at the end of the second period.

TABLE IV-Relation between guess about current treatment (cimetidine or placebo) and weight loss during the first eight week period of treatment (women only)

\begin{tabular}{lcc}
\hline & Mean (SD) weight loss & No of patients \\
\hline All guesses: & & \\
Cimetidine & $6 \cdot 2(3 \cdot 1)$ & 9 \\
Placebo & $5 \cdot 0(2 \cdot 3)$ & 22 \\
Unable to guess & $5 \cdot 2(2 \cdot 4)$ & 16 \\
Correct guesses: & & \\
$\quad$ Cimetidine & $6 \cdot 0(3 \cdot 2)$ & 7 \\
$\quad$ Placebo & $5 \cdot 8(2 \cdot 0)$ & 14 \\
Wrong guesses: & $7 \cdot 0(3 \cdot 5)$ & 2 \\
$\quad$ Cimetidine & $3 \cdot 6(2 \cdot 4)$ & 8 \\
Placebo & & \\
\hline
\end{tabular}

TABLE V-Number of patients reporting side effects

\begin{tabular}{cccccc}
\hline & \multicolumn{2}{c}{ Cimetidine } & & \multicolumn{2}{c}{ Placebo } \\
\cline { 2 - 3 } \cline { 5 - 6 } \cline { 5 - 7 } Side effect & $\begin{array}{c}\text { First } \\
\text { period } \\
(\mathrm{n}=30)\end{array}$ & $\begin{array}{c}\text { Second } \\
\text { period } \\
(\mathrm{n}=42)\end{array}$ & & $\begin{array}{c}\text { First } \\
\text { period } \\
(\mathrm{n}=30)\end{array}$ & $\begin{array}{c}\text { Second } \\
\text { period } \\
(\mathrm{n}=13)\end{array}$ \\
\hline
\end{tabular}

\begin{tabular}{lllll}
\hline Dizziness & 0 & 1 & 0 & 0
\end{tabular}

Anxiety

Depression

Headache

Constipation

Nausea

Nausea

Abdominal pains

Rhinitis

Pharyngitis

Tonsillitis

Sinusitis

Influenza

Psoriasis

Anaemia

$\begin{array}{llll}0 & 1 & 0 & 0 \\ 0 & 1 & 0 & 0 \\ 0 & 1 & 0 & 0 \\ 4 & 6 & 7 & 2 \\ 6 & 5 & 4 & 3 \\ 4 & 3 & 2 & 0 \\ 0 & 2 & 0 & 0 \\ 3 & 5 & 1 & 0 \\ 0 & 1 & 0 & 0 \\ 0 & 1 & 0 & 0 \\ 1 & 0 & 2 & 0 \\ 1 & 0 & 0 & 0 \\ 1 & 0 & 0 & 1 \\ 0 & 1 & 0 & 0 \\ 0 & 1 & 0 & 0\end{array}$

Only side effects reported by one or more patients in the cimetidine group have been included (all 60 patients reported at least one side effect).

guesses were considered or when only correct guesses were included. However, weight losses tended to be high for patients who guessed cimetidine wrongly and low for those who wrongly guessed placebo (table IV). After the first period, 11 patients indicated that their suspension tasted like medicine or had side effects. Seven of these patients put forward a guess of their current medication; six guessed cimetidine and one guessed placebo because of lack of effect. All seven guesses were correct $(p=0.02)$. Table $V$ lists the number of patients reporting side effects.

\section{Discussion}

In contrast to a recent Norwegian study, ${ }^{1}$ we found no effect of cimetidine on either weight loss or perception of hunger in obese patients. The second phase of the trial, with crossover or continuation of drug treatment, seemed to confirm the inefficiency of cimetidine as adjuvant to a diet in treating obesity (fig 3).

The Norwegian study included 60 overweight subjects and was a double blind, randomised, placebo controlled trial,' designed like the first period of our study. The cimetidine and placebo suspensions were also identical to those used in our study. However, the 
mean weight loss in the Norwegian study was significantly higher in the cimetidine group than in the placebo group (difference $=7.3 \mathrm{~kg}, \mathrm{p}<0.001,95 \%$ confidence interval $6 \cdot 4$ to $8 \cdot 2$ ). A weight reducing effect of $7.3 \mathrm{~kg}$ over eight weeks is much greater than that achieved with any other previously tested antiobesity drug.

The second aim of our study was to evaluate the success of the blinding and its relation to weight loss. The double blind, randomised trial is considered the gold standard for therapeutic research. ${ }^{6-8}$ In contrast to recommendations, ${ }^{910}$ however, the effectiveness of the blinding has only rarely been tested and related to outcome. In a placebo controlled study of the effect of vitamin $C$ on the common cold, an apparent dose related effect on the duration of symptoms was noted, but the effect disappeared when subjects identifying the vitamin by its special taste were excluded. ${ }^{10}$ Our results indicate that unblinding may be particularly likely to invalidate studies with a crossover design. Unfortunately, crossover studies are often insufficiently analysed..$^{12}$ Since data from the two periods are often pooled, unrecognised bias caused by unblinding during the second period can make the whole study unreliable.

In a study of fenfluramine and placebo in obesity $71 \%$ of the patients correctly identified their treatment, most because of side effects of the active drug. ${ }^{14}$ Fenfluramine was effective, and there was a tendency towards a greater weight loss in patients taking fenfluramine who gave correct guesses. However, this tendency was also noted for patients receiving placebo. Unfortunately, the number of patients was too small to allow a meaningful comparison of fenfluramine and placebo in this respect, since only three patients taking the drug and three taking placebo guessed wrongly.

We found cimetidine to be inefficient as a treatment for obesity. Despite the fact that the drug had only few side effects, our patients guessed their therapy (cimetidine or placebo) correctly more often than expected by chance, especially during the second period of treat- ment. Our patients were seen in groups and were able to exchange experiences and suggestions. Therefore, patients obtaining a better than average weight loss would be expected to believe they were being given cimetidine. However, this was not so. The "placebo effect," calculated as the difference in mean weight loss between those who believed they were receiving active treatment and those who believed they were receiving placebo, was insignificant, being only $1.2 \mathrm{~kg}(-0.8 \mathrm{~kg}$ to $3.2 \mathrm{~kg}$ ). In accordance with international manuscript guidelines ${ }^{10}$ we suggest that the success of the blinding be routinely included as an important variable in controlled clinical trials.

We thank the clinical dietitians Grete Hansen and Anne W Rasmussen for their skilled help.

1 Stoa-Birketvedt G. Cimetidine suspension reduces appetite and weight in dieting overweight subjects [abstract]. Int $\mathcal{F}$ Obesity 1991;15(suppl 3):19.

2 Hey H, Peterson HD, Andersen T, Quaade F. Formula diet plus free additional food choice up to $1000 \mathrm{kcal}(4 \cdot 2 \mathrm{MJ})$ compared with an additional food choice up to $1000 \mathrm{kcal}(4 \cdot 2 \mathrm{MJ})$ compared with an
isoenergetic conventional diet in the treatment of obesity. A randomised clinical trial. Clin Nutr 1986;6:195-9.

3 Andersen T, Astrup A, Quaade F. Dexfenfluramine as adjuvant to a lowcalorie formula diet in the treatment of obesity: a randomized clinical trial. Int $\mathcal{O}$ Obesity 1992;16:35-40.

4 Seidell JC, Cigolini M, Charzewska J, Ellsinger BM, Contaldo F. Regional obesity and serum lipids in European women born in 1948. Acta Med Scand 1988; Suppl 723:189-97.

5 Armitage P, Berry G. Statistical methods in medical research. Oxford: Blackwell, 1987

6 Lasagna L. The controlled clinical trial. 7 Chronic Dis 1955;1:353-67.

$7 \mathrm{Nash} \mathrm{H}$. The design and conduct of experiments on the psychological effects of drugs. 7 Nerv Ment Dis 1959;128:1239-45.

$8 \mathrm{Nash} \mathrm{H}$. The double-blind procedure: rationale and empirical evaluation. INerv .

9 Cromie $\mathrm{BW}$, Lond MB. The feet of clay of the double-blind trial. Lancet 1963;i:994-7.

10 International Committee of Medical Journal Editors. Uniform requirements for manuscripts submitted to biomedical journals. BMf 1988;296:401-5.

11 Karlowski TR, Chalmers TC, Frenkel LD, Kapikian AZ, Lewis TL, Lynch $\mathrm{JM}$. Ascorbic acid for the common cold. A prophylactic and therapeutic trial. $\mathscr{\text { f }}$ AMA 1975;231:1030-42.

12 Louis TA, Lavori PW, Bailar JC, Polansky M. Crossover and self-controlled designs in clinical research. $N$ Engl f Med 1984;310:24-31.

13 Gotzsche PC. Methodology and overt and hidden bias in reports of 196 doubleblind trials of nonsteroidal, antiinflammatory drugs in rheumatoid arthritis. Controlled Clin Trials 1989;10:31-56,356.

14 Brownell KD, Stunkard AJ. The double-blind in danger: untoward consequences of informed consent. Am $\mathcal{F}$ Psychiatry 1982;139:1487-9.

(Accepted 22 March 1993)

\title{
Modified paediatric resuscitation chart
}

\author{
Derek P Burke, David F Bowden
}

Accident and Emergency

Department, Royal Hospital, Wolverhampton WV2 1BT

Derek P Burke, registrar

Accident and Emergency Department, Dudley Road Hospital, Birmingham B18 7QH

David F Bowden, senior registrar

Correspondence to:

Dr Burke.
Abstract

Objectives-To determine whether a modified paediatric resuscitation reference chart improves the speed and accuracy of calculation of doses of drugs in simulated paediatric cardiopulmonary arrests when compared with the chart devised by Oakley.

Design-A prospective study in which a series of randomly assigned questions was used to compare the performance of doctors using the two charts.

Setting-Accident and emergency departments in two hospitals.

Subjects-31 senior house officers.

Main outcome measures-The speed and accuracy of calculation of volumes of drugs to be administered.

Results-The modified chart significantly increased the accuracy of the calculations (62/62 $v$ 43/ $62, p<0.05)$, the speed of correct calculations $(6.8 \mathrm{~s} v$ $36.0 \mathrm{~s}, \mathrm{p}<0.0001$ ), and the number of calculations that were completed $(62 / 62 v 50 / 62, \mathrm{p}<0 \cdot 001)$.

Conclusions-The modified paediatric resuscitation chart should supersede the existing chart.

\section{Introduction}

Paediatric cardiopulmonary arrest is an uncommon occurrence which any doctor may be called on to manage. Oakley reported problems in treating this condition and identified two main factors contributing to delays in making decisions. ${ }^{1}$ The first is the wide variation in the weights of children of different ages, making selection of the correct dose of drug difficult when a child's weight or age is unknown. The second is the infrequency of cardiopulmonary arrest in children, resulting in a tendency for doctors to forget recommended doses. Oakley asked 34 junior doctors of various grades and specialties about their knowledge of doses of drugs, sizes of endotracheal tubes, and defibrillation energy for children of various ages and weights. The results of his study led him to devise a reference chart, which was produced by the $B M F$ (figure). Although this chart is widely used, no studies evaluating its use have been published.

We have observed the use of the chart in several accident and emergency departments and found the following problems: some of the doses of drugs on the 